структурний елемент сучасної ринкової економічної системи.

Важлива функція малого підприємництва - сприяння соціально-політичної стабільності суспільства, тобто воно відкриває простір вільному вибору шляхів і методів роботи на користь суспільства та забезпечення власного добробуту. Тому реалізовувати освітянські виклики ринкової економіки і належить широкій безперервній економічній освіті.

Отже, мале підприємництво $є$ невід'ємною рисою будь-якої ринкової господарської системи, без чого така економіка і суспільство в цілому розвиваються.

\title{
Література
}

1. Закон України «Про підприємництво» // Галицькі контракти. - 1998. - № 8. С. 129-159. 2. Варналій 3. С. Основи підприємницької діяльності : підручник [для учнів 10-11 кл.] / З. С. Варналій, В. О. Сизоненко. - К. : Знання України; 2004. - 404 с. 3. Вачевський М. В. Основи економіки : [навч. посіб.]/ М. В. Вачевський, В. М. Мадзігон. - К. : Педагогічна думка; 2007. - 612 с. 4. Гальчинський А. С. Основи економічних знань / Гальчинський А. С., Сщенко П. С., Палкін Ю. І. -К. : Вища школа, 1998. - 544 с. 5. Кулішов В. В. Основи економічної теорії : підручник [для студентів вищих закладів освіти] / В. В. Кулішов. - Львів : Магнолія 2006, 2007. 516 с. 6. Кулішов В. В. Основи ринкової економіки : [підручник] / Кулішов В. В., Падалка О. С., Вачевський М. В. - Львів : Магнолія, 2013. - 472 с. 7. Михасюк І. Р. Українське підприємництво в умовах глобалізації / І. Р. Михасюк, І. М. Бернацький. Львів, 2008. - 56 с. 8. Маниліч М. І. Основи ринкового механізму господарювання : [навч. посіб.] / М. І. Маниліч, І. В. Губатюк. - К., 1992. - 174 с. 9. Мадзігон В. М. Продуктивна педагогіка : [монографія] / В. М. Мадзігон. - К. : Вересень. - 2004. 324 с. 10. Мочерний С. В. Основи економічної теорії / С. В. Мочерний. - К. : Академія. $-1997 .-464$ с.

УДК. 371.13

Олексій Мельник

\section{УПРОВАДЖЕННЯ ДИСТАНЦЙНОГО КУРСУ ЯК ЗАСІБ ПІДВИЩЕННЯ ЯКОСТІ ОСВІТИ У ПРОФЕСІЙНІЙ ПІДГОТОВЦІ МАЙБУТНІХ ФАХІВЦІВ}

Мельник О. С. Упровадження дистанційного курсу як засіб підвищення якості освіти у професійній підготовці майбутніх фахівців.

У статті обгрунтовано доцільність упровадження дистанційної освіти в контексті підготовки інженерів-технологів та викладачів професійно-технічних навчальних закладів. На прикладі розроблення навчально-методичного забезпечення дисципліни «WEB-технології та WEB-дизайн» наведено переваги використання середовища дистанційного навчання Moodle.

Ключові слова: професійна освіта, комп'ютерні технології, інженер-технолог, «WEB-технології та WEB-дизайн», Moodle.

Мельник О. С. Внедрение дистанционного курса как средство повышения качества образования в профессиональной подготовке будущих специалистов.

В статье обусловлена целесообразность внедрения дистанционного образования в контексте подготовки инженеров-технологов и преподавателей профессиональнотехнических учебных заведений. На примере разработки учебно-методического обеспечения дисциплины «WEB-технологии и WEB-дизайн» приводятся 
преимущества использования среды дистанционного обучения Moodle.

Ключевые слова: профессиональное образование, компьютерные технологии, инженер-технолог, «WEB-технологии и WEB-дизайн», Moodle.

Melnik O. S. Introduction of the controlled from distance course as means of upgrading of education is in professional preparation of future specialists

In the article expediency of introduction of the controlled from distance education is presented in the context of preparation of engineers-technologists and teachers of vocational educational establishments. On the example of development of the educational and methodical providing of discipline of «WEB- technologies and WEB-design» advantages over of the use of environment of the controlled from distance studies of Moodle are brought.

Key words: trade education, computer technologies, engineer-technologist, «WEBtechnologies and WEB-design», Moodle.

Зростання інтелектуалізації галузей і технологій зумовлює зростання попиту на професійні та висококваліфіковані кадри. Роботи 3 інтеграції нових інформаційних технологій до освітнього процесу як для розвитку адаптивних методів навчання i реалізації дистанційної освіти видаються перспективними [4-7].

Аналіз досліджень у цій галузі показав наявність двох напрямків розроблення програмного забезпечення: інформаційно-освітнього середовище, що забезпечує підтримку організаційно-методичного комплексу дисциплін; навчальні системи, які спрямовані на розв'язання специфічних проблем окремо взятої дисципліни [8].

Тому, метою статmі $\epsilon$ науково-теоретичне обгрунтування розроблення дистанційного курсу «WEB-технології та WEB-дизайн» в інформаційно-навчальному середовищі Moodle.

В ієрархії методичних матеріалів дистанційного навчання дистанційний курс за обсягом і за ступенем відображення навчального матеріалу посідає проміжне місце між курсовим проектом та електронним підручником. Зважаючи на аналогію, дистанційний курс можна назвати путівником 3 навчальної дисципліни 3 усіма притаманними їй атрибутами. Фактично дистанційний курс - це розроблена 3 певним ступенем покрокова інструкція із засвоєння курсу, сформульована у його описі [7].

Як правило, дистанційні курси розробляються за допомогою різних програмних продуктів, що дозволяють представляти його вміст у форматах Інтернету (HTML). Це можуть бути як найпростіші розробники веб-сайтів, убудовані в текстові редактори, так і такі програми, як MS FrontPage, MS Publisher та ін. Курси можуть розроблятися i за допомогою спеціальних програм-оболонок, призначених для дистанційного навчання (WebCT, Lotus Learning Space, BlackBoard, Moodle, Доцент, Прометей тощо) [1;9]. Відмінність лише в тому, що у спеціальних програмах відразу задається шаблон структури курсу.

Процес розроблення курсу чітко ділиться на дві частини: розроблення методичного наповнення і дизайн-курсу. Причому термін «дизайн» розуміється у двох аспектах. 3 одного боку, це методичний дизайн- структурування текстів, логічне вибудовування їх частин, проектування структури понятійно-категоріального апарату й інструментальної частини курсу- контролів, обговорень, оціночних критеріїв тощо. Важлива частина методичного дизайну - формування гіпертекстової структури курсу, тобто системи покликань і переходів між поняттями, змістовними й інструментальними блоками. 3 іншого боку, дизайн-це «вбудовування» текстів, 
написаних викладачем i оброблених методистом, у стандартну веб-структуру, формування системи навігації і посилань.

Отже, дистанційний курс становлять особливим способом сконструйований вебсайт, що складається 3 низки сторінок-розділів.

Комплект навчально-методичних матеріалів дистанційного курсу повинен розроблятися відповідно до принципів:

1. Програма дистанційного курсу повинна містити цілі навчального процесу 3 цієї дисципліни, формувати мотивації успішного вивчення курсу за допомогою роз'яснення іiі місця і значення в системі навчання. Перелік тем у дистанційному курсі доцільно супроводити вказівкою необхідного рівня засвоєння матеріалу.

2. Навчальні матеріали в цифровій формі з використанням гіпертексту повинні задовольняти вимогу простоти орієнтації студентів під час переміщення по покликаннях. У передмові до навчальних матеріалів необхідно пояснити умовні позначення покликань і надати поради щодо раціональних прийомів навігації.

3. Дистанційний курс повинен передбачати спілкування студентів з викладачем і між собою.

4. Дистанційний курс не є електронною копією друкованих підручників або простим комп'ютерним підручником. Інформаційно-комунікаційні технології можуть і повинні ефективно використовуватися задля досягнення мети навчального процесу.

Задля виявлення можливості інтеграції будь-якого курсу до системи електронної підтримки навчання на основі Moodle, обрано курс $з$ дисципліни «WEB-технології та WEB-дизайн». Вибір був зумовлений такими чинниками: великий набір електронних матеріалів; функціонування системи тестування; наявність презентацій для експорту в MOODLE.

Ця дисципліна складається 3 повного курсу лекційних занять, що викладаються в аудиторії шляхом демонстрації слайдів та іншого текстографічного контенту, набору тестів, лабораторних робіт.

Особливість дистанційного навчального модуля повинна полягати в такому: наявність курсу навчання; наявність відеолекцій; можливість проведення он-лайн навчання; продемонструвати сучасні програмні засоби для створення комунікативного класу; містити елементи управління навчанням; розмежування прав доступу до модуля тестування; модель повинна мати привабливий вигляд.

Під час реалізації навчальних програм особливого значення набувають технології подання освітньої інформації, які й забезпечують процес навчання та його підтримку. Вибираючи такі технології, необхідно враховувати специфічні особливості конкретних предметних галузей, типів навчальних завдань, вправ [2].

Задля розроблення навчального курсу використовувалися тільки нові актуальні матеріали та розробки. Упровадження цього комплексу в навчальний процес суттєво поліпшить програмно-методичне забезпечення 3 цієї дисципліни. Навчальний комплекс надає студенту нові засоби доступу до інформації та забезпечує опанування активної форми навчання. У таких умовах набуває розвитку самостійність студента щодо керування процесом навчання й контролю за його результативністю.

Модель навчального комплексу складається 3 чотирьох функціональноузгоджених модулів: навчально-методичного, контрольно-комунікативного, організаційно-змістовного та інформаційно-довідкового.

Організаційно-змістовний модуль містить навчальний план для підготовки спеціалістів з напряму «Професійна освіта. Комп’ютерні технології»; інформацію про мету, навчальні завдання, терміни вивчення курсу, програмний матеріал, що визначає 
зміст і обсяг вивчення дисципліни; навчальну та робочу програми курсу «WEBтехнології та WEB-дизайн».

Навчально-методичний модуль охоплює: лекційні матеріали відповідно до робочої програми, зазначеної в організаційно-змістовому модулі; план проведення лабораторних занять із зазначенням послідовності тем занять та необхідними матеріалами для підготовки до лабораторних робіт - короткі теоретичні та навчально-методичні матеріали до кожної із тем роботи; план оформлення звіту з роботи, приклади виконання завдань, опис матеріально-технічного забезпечення лабораторних занять із курсу «WEB-технології та WEB-дизайн». Матеріали комплексу оформлюються за допомогою гіпертекстової розмітки 3 подальшою компіляцією в єдиний комплекс 3 можливістю редагування (рис. 1).

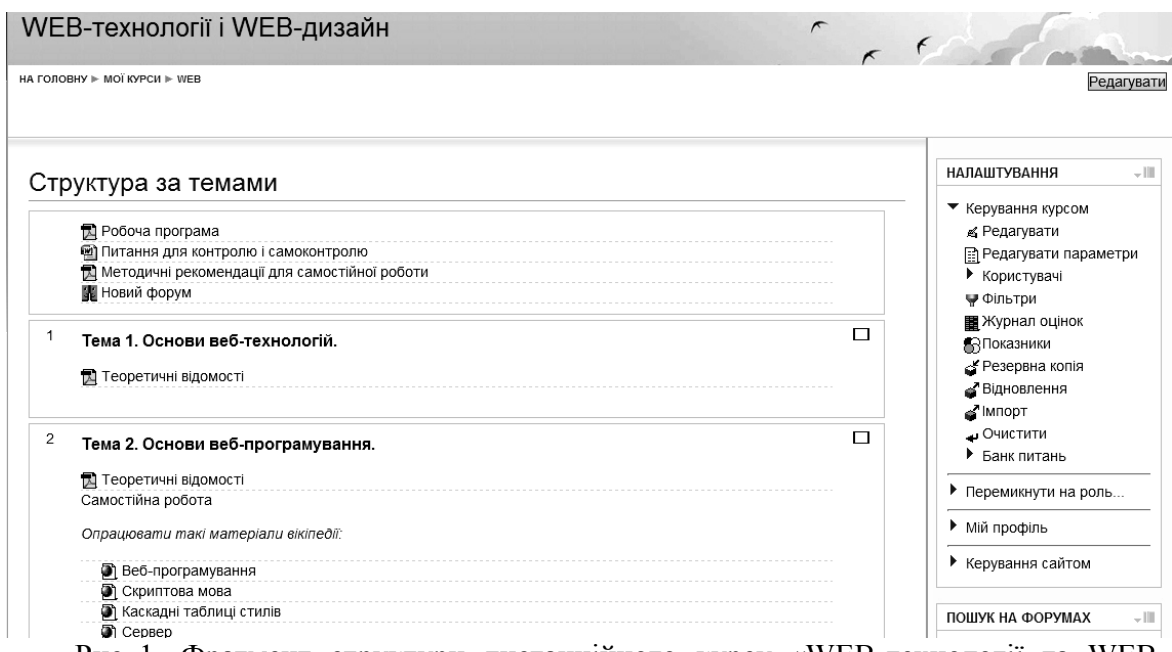
дизайн»

Рис. 1. Фрагмент структури дистанційного курсу «WEB-технології та WEB-

Матеріали комплексу підібрані так, щоб оптимально організувати процес вивчення дисципліни; адаптувати процес навчання й календарний план згідно зі своїми індивідуальними навичками; надають змогу більш глибоко вивчити питання, що розглядаються на лекціях, та більш детально ознайомитися 3 питаннями, які відпрацьовуються на лабораторних роботах.

До складу інформаційно-довідкового модуля входять: електронна бібліотека перелік покликань на електронні підручники, навчально-методичні посібники та довідники з курсу.

Контрольно-комунікативний модуль містить: питання для перевірки знань, подані за темами курсу; тести для поточного та підсумкового контролю.

Система тестування, крім поділу за темами, дозволяє також формувати завдання 3 динамічно сформованим переліком питань, обраних за рівнем складності. Під час тестування пропонується певна кількість запитань. Тестові завдання мають перелік варіантів відповідей та одну правильну відповідь. Тести в модулі тестування формуються за випадковим критерієм і кожне питання вибирається випадково, тому чим більшою $є$ база питань, тим більша вибірка тестових завдань та менша ймовірність того, що студенту попадеться одне питання двічі при подальших 
проходженнях тесту.

Результати тестування виводяться на окремій сторінці у вигляді невеликої статистики. У цій статистиці зазначається: кількість питань, кількість правильних відповідей, відсоток успішності, питання, на яке подається неправильна відповідь із зазначенням неправильної відповіді. Цей спосіб буде спонукати студента повторно перечитати пройдений матеріал та знайти правильну відповідь, а не просто запам'ятати ії з тесту.

Модуль призначений для визначення студентом глибини розуміння матеріалу та готовності до переходу студента до іншої теми курсу; для визначення рівня навчальних досягнень студента по завершенню вивчення курсу; для реалізації додаткових комунікаційних можливостей між студентом та викладачем засобами електронного зв'язку.

Розроблений навчально-методичний комплекс $\epsilon$ зручним інструментом програмно-методичного забезпечення навчального процесу під час вивчення студентами технічних спеціальностей дисципліни «WEB-технології та WEB-дизайн», надає широкі можливості для проведення тестування, допомагає оптимізувати навчальний процес, підвищує пізнавальну активність студентів. Це у свою чергу забезпечує високий рівень засвоєння знань 3 курсу і дозволяє використовувати технології дистанційного навчання через мережу Internet, що значно розширює можливості для самостійної роботи студентів.

У ході виконання дослідження розглянуті різні методи впровадження та створення моделі комунікативного класу. На прикладі впровадження курсу 3 дисципліни «WEB-технології та WEB-дизайн» були виявлені специфічні особливості використання CMS Moodle як системи електронної підтримки навчання: ця система $\epsilon$ потужним інструментом 3 надання електронної підтримки навчання студентів. Для коректного використання цієї системи необхідно вивчити документацію і трохи розібратися 3 настройками елементів і блоків; при використанні презентацій у реальному курсі рекомендується використовувати покликання на додаткові матеріали i ресурси або у вигляді елемента «Пояснення» до блоку, або у вигляді елемента «Лекція»; під час проведення багатьох курсів викладачеві можуть допомогти відеоуроки, розроблені студентами і дібрані в Інтернеті; слід використовувати можливості форуму і блоку особистих повідомлень для спілкування зі студентами.

\section{Література}

1. Анисимов А. П. Работа в системе дистационного обучения Moodle: [ учеб. пособ]. / А. П. Анісімов. - [2-е изд., испр. и доп.]. - Харьков : ХНАГХ, 2009. - 292 с. 2. Беспалько В. П. Образование и обучение с участием компьютеров (педагогика третьего тысячелетия)/ $\quad$ В. П. Беспалько. - М.: Воронеж, 2002. - 260 с. 3. Захарова И. Г. Информационные технологии в образовании: учеб. пособие [для студ. высш. пед. учеб. заведений] / И. Г. Захарова. - М. : Издательский центр «Академия», 2003. - 192 с. 4. Норенков И. П. Информационные технологии в образовании / И. П. Норенков, А. М. Зимин. - М. : Изд-во МГТУ им. Н. Э. Баумана, 2004. - 352 с. 5. Норенков И. П. Системные вопросы дистанционного обучения / И. П. Норенков // Системы открытого образования: электр. журнал. - М. : МГТУ им. Н. Э. Баумана. - Режим доступа: http://www.engineer.bmstu.ru. - Загл.с экрана. 6. Норенков И. П. Управление знаниями в информационно-образовательной среде / И. П. Норенков // Системы открытого образования: электр. журнал. - М. : МГТУ им. Н. Э. Баумана. - Режим доступа : http://www.engineer.bmstu.ru. - Загл.с экрана. 7. Про затвердження Положення про дистанційне навчання. Наказ МОН № 466 від 
25.04.13 року [Електронний ресурс]. - Режим доступу: http://osvita.ua/legislation/Dist_osv/2999/. 8. Солдатки В. И. Образовательная среда сегодня и завтра / В. И. Солдаткин. - М. : Рособразование, 2004. - 272 с. 9. Terasic Technologies. Altera DE0 User Manual 2011. - 53. www.altera.com.

УДК 37.015.31:57.081.1

Евген Силко

\section{ЕКОЛОГІЯ КУЛЬТУРИ ЯК НАЦІОНАЛЬНО ОРІЕНТОВАНА ПЕРСПЕКТИВА КУЛЬТУРОВІДПОВІДНОГО ВИХОВАННЯ ПІДРОСТАЮЧОГО ПОКОЛІННЯ В УМОВАХ ГЛОБАЛІЗАЦЇ̈}

Силко С. М. Екологія культури як національно орієнтована перспектива культуровідповідного виховання підростаючого покоління в умовах глобалізації.

Статтю присвячено актуальній проблемі збереження природи народу (етноприроди) в умовах всеохоплюючих глобалізаційних процесів. Культуровідповідне виховання позиціонується як один із найефективніших інструментів гуманізації й екологізації соціально-культурного середовища, надання йому духовного осмислення.

Ключові слова: культура, глобалізація, екологія, виховання, духовність.

Силко Е. Н. Экология культуры как национально ориентированная перспектива культуросообразного воспитания подрастающего поколения в условиях глобализации.

Статья посвящена актуальной проблеме охраны природы народа (этноприроды) в условиях всеобъемлющих глобализационных процессов. Культуросообразное воспитание позиционируется как один из наиболее эффективных инструментов гуманизации и экологизации социально-культурной среды, придание ей духовной осмысленности.

Ключевые слова: культура, глобализация, экология, воспитание, духовность.

Sylko E. M. Ecology of culture as a national oriented perspective of the cultural upbringing of the younger generation in the context of globalization.

The article is dedicated to the actual problem of nature of the people protection in ecology culture. Upbringing in accordance with the nature is positioned as one of the most effective tools of humanization and greening of the socio-cultural environment, giving it a spiritual meaning.

Key words: culture, globalization, ecology, education, spirituality.

Нині все більше уваги звертається на два основні чинники сучасного світового процесу, що здатні вплинути на розвиток культури загалом та освіти й виховання зокрема. 3 одного боку, це бурхливий розвиток науково-технічного прогресу та процесів глобалізації, а з іншого,- викликані ними соціальні й екологічні проблеми. Наука i техніка в сучасному суспільстві дистанціювалися від людини, а технократичне мислення починає втрачати те мірило, яке повинно характеризувати будь-яку форму людської діяльності, що має гуманістичну спрямованість. Іншими словами, ця дистанція нівелює духовність і моральність як домінанти людського існування.

Проблема взаємозв'язку людини 3 культурним середовищем відповідної спільності ставала предметом дослідження науковців найрізноманітніших галузей 